\title{
Glycine/Glycolic Acid Based Copolymers
}

\author{
PETER J. A. IN 'T VELD, ZHENG-RONG SHEN, * GIJSBERT A. J. TAKENS, PIETER J. DIJKSTRA, and JAN FEIJEN ${ }^{\dagger}$ \\ Department of Chemical Technology, University of Twente, P.O. Box 217, 7500 AE Enschede, Netherlands
}

\begin{abstract}
SYNOPSIS
Glycine/glycolic acid based biodegradable copolymers have been prepared by ring-opening homopolymerization of morpholine-2,5-dione, and ring-opening copolymerization of morpholine-2,5-dione and glycolide. The homopolymerization of morpholine-2,5-dione was carried out in the melt at $200^{\circ} \mathrm{C}$ for $3 \mathrm{~min}$ using stannous octoate as an initiator, and continued at lower reaction temperatures $\left(100-160^{\circ} \mathrm{C}\right)$ for $2-48 \mathrm{~h}$. The highest yields $(60 \%)$ and intrinsic viscosities $\left([\eta]=0.50 \mathrm{dL} / \mathrm{g} ; \mathrm{DMSO}, 25^{\circ} \mathrm{C}\right)$ were obtained after 3 min reaction at $200^{\circ} \mathrm{C}$ and $17 \mathrm{~h}$ at $130^{\circ} \mathrm{C}$ using a molar ratio of monomer and initiator of 1000 . The polymer prepared by homopolymerization of morpholine-2,5-dione was composed of alternating glycine and glycolic acid residues, and had a glass transition temperature of $67^{\circ} \mathrm{C}$ and a melting temperature of $199^{\circ} \mathrm{C}$. Random copolymers of glycine and glycolic acid were synthesized by copolymerization of morpholine-2,5-dione and glycolide in the melt at $200^{\circ} \mathrm{C}$, followed by $17 \mathrm{~h}$ reaction at $130^{\circ} \mathrm{C}$ using stannous octoate as an initiator. The morphology of the copolymers varied from semi-crystalline to amorphous, depending on the mole fraction of glycolic acid residues incorporated. (c) 1994 John Wiley \& Sons, Inc.

Keywords: biodegradable polymers $\bullet$ glycine $\bullet$ glycolic acid $\bullet$ morpholine-2,5-dione $\bullet$ glycolide - ring-opening polymerization
\end{abstract}

\section{INTRODUCTION}

Poly ( $\alpha$-hydroxy acid )s and poly ( $\alpha$-amino acid $) \mathrm{s}$ are two important classes of synthetic biodegradable polymers, which are currently investigated and applied for a wide variety of surgical and pharmaceutical applications. ${ }^{1,2}$ Polydepsipeptides, copolymers of $\alpha$-hydroxy acids and $\alpha$-amino acids, are the most important representatives of biodegradable polyesteramides. These polymers have been prepared by polymerization of di-, tri-, tetra-, and pentadepsipeptide activated esters. ${ }^{3-7}$ The necessary di-, tri-, tetra-, and pentadepsipeptide monomeric units were synthesized via multistep synthetic routes.

The ring-opening polymerization of cyclic didepsipeptides (morpholine-2,5-dione derivatives) is an attractive alternative method to prepare polydepsipeptides in a more facile way. ${ }^{8,9}$ Ring-opening polymerization of morpholine-2,5-dione derivatives

\footnotetext{
* Present address: Institute of Family Planning Research, Zhejiang Academy of Medicine, Hangzhou, China.

${ }^{\dagger}$ To whom all correspondence should be addressed.

Journal of Polymer Science: Part A: Polymer Chemistry, Vol. 32, 1063-1069 (1994) (C) 1994 John Wiley \& Sons, Inc. CCC 0887-624X/94/061063-07
}

provides a method to prepare a wide range of biodegradable polyesteramides, because various different $\alpha$-amino acid residues can be incorporated into morpholine-2,5-dione derivatives, and these monomers can be copolymerized with other lactones. ${ }^{10-13}$

A large number of alternating polydepsipeptides has been reported in the literature. The preparation of poly (glycine-alt-glycolic acid), which consists of the basic chemical structure of this class of polymers, has only been mentioned once in the literature. ${ }^{3}$ The polymer was synthesized by polymerization of the corresponding didepsipeptide $p$-nitrophenyl ester, but was only poorly characterized. Poly (glycine-altglycolic acid) consists of a polymer chain without side groups. Therefore it may be expected that the polymer will crystallize. This and the hydrophilic nature of the glycine and glycolic acid residues constituting the polymer backbone makes the polymer a particularly interesting candidate for application as a biodegradable material with a relatively short degradation time. Whereas the ring-opening copolymerization of $p$-dioxanone with small quantities of morpholine-2,5-dione ( $<10 \mathrm{~mol} \%$ ) has been reported, ${ }^{14}$ the homopolymerization of morpholine- 
2,5-dione is still missing in the literature. This prompted us to investigate the synthesis of poly (glycine-alt-glycolic acid) by ring-opening polymerization of morpholine-2,5-dione.

In this article we report on the synthesis of poly (glycine-alt-glycolic acid) and glycine/glycolic acid based copolymers by ring-opening homopolymerization of morpholine-2,5-dione and the ringopening copolymerization of morpholine-2,5-dione and glycolide, respectively.

\section{EXPERIMENTAL}

\section{Materials}

$N$-(chloroacetyl)glycine and stannous octoate were purchased from Sigma Chem. Corp. (St. Louis, MO) and used as received. Glycolide (Boehringer, Ingelheim, Germany ) was recrystallized from ethyl acetate and dried over $\mathrm{KOH}$ in vacuo. DMSO was dried over molecular sieves ( $3 \AA$ ) before use.

\section{Methods}

${ }^{1} \mathrm{H}$ - and ${ }^{13} \mathrm{C}$ - NMR spectroscopy was performed with a Bruker AC 250 spectrometer, using DMSO- $d_{6}$ as a solvent and tetramethylsilane as an internal standard.

Intrinsic viscosities $([\eta])$ were determined by the usual extrapolation to zero concentration method, using a Cannon microviscometer thermostated at $25^{\circ} \mathrm{C}$, and $0.5,0.35$, and $0.25 \%(\mathrm{w} / \mathrm{v})$ polymer solutions in DMSO.

Elemental analyses were carried out by the Laboratory of Chemical Analysis of the University of Twente.

Differential scanning calorimetry (DSC) measurements were performed with a Perkin Elmer DSC-7 apparatus calibrated with indium and gallium. Samples of the (co) polymers $(10 \mathrm{mg}$ ) were quenched to $-10^{\circ} \mathrm{C}$ and kept at this temperature for $5 \mathrm{~min}$. Subsequently, the samples were heated to $220^{\circ} \mathrm{C}$ at a rate of $20^{\circ} \mathrm{C} / \mathrm{min}$ (first scan ). Thereafter the samples were quenched to $-10^{\circ} \mathrm{C}$, kept at this temperature for $5 \mathrm{~min}$, and heated again to $220^{\circ} \mathrm{C}$ at a rate of $20^{\circ} \mathrm{C} / \mathrm{min}$ (second scan).

\section{Preparations}

\section{Morpholine-2,5-dione 2}

A solution of $25.0 \mathrm{~g}(0.165 \mathrm{~mol}) \mathrm{N}$-(chloroacetyl) glycine (1) in $200 \mathrm{~mL}$ of water was adjusted to pH 7.0 by slow addition of a $3 M \mathrm{NaOH}$ solution.
The solution was concentrated in vacuo to give a syrup. The syrup was stripped three times with ethanol to yield the hygroscopic sodium salt. The salt was dissolved in $200 \mathrm{~mL}$ of methanol, $50 \mathrm{~g}$ of Celite $^{\circledR} 545$ was added and the methanol was evaporated. To the residue $200 \mathrm{~mL}$ of methanol was added and the solvent was evaporated again. This procedure was repeated once more. To this residue $200 \mathrm{~mL}$ of diethyl ether was added and the solvent was evaporated. This procedure was repeated once more to give a dry powdery product. After drying for $48 \mathrm{~h}$ over $\mathrm{KOH}$ in vacuo, the mixture was quickly transferred to a sublimator and dried for another 2 $\mathrm{h}$ at $80^{\circ} \mathrm{C}$ in vacuo $(P=0.05 \mathrm{mBar})$. Next the temperature was raised to $150^{\circ} \mathrm{C}$, whereupon a small amount of morpholine-2,5-dione sublimed. After 2 h $1.50 \mathrm{~g}$ of $\mathrm{Sb}_{2} \mathrm{O}_{3}$ was mixed with the residue, and the reaction was continued at $230^{\circ} \mathrm{C}$ in vacuo until no more product sublimed (ca. $2 \mathrm{~h}$ ). The sublimate was collected and recrystallized from acetonitril to yield $3.0 \mathrm{~g} \mathrm{(16 \% )} \mathrm{of} \mathrm{morpholine-2,5-dione} \mathrm{(2).}$ mp $192-193^{\circ} \mathrm{C}$ (lit ${ }^{14} \mathrm{mp} 194-196^{\circ} \mathrm{C}$ ). ${ }^{1} \mathrm{H}-\mathrm{NMR}$ $\left(\mathrm{DMSO}-d_{6}\right): \delta=4.08\left(\mathrm{~s}, 2 \mathrm{H}, \mathrm{NHC}_{2}\right), 4.72(\mathrm{~s}, 2 \mathrm{H}$, $\left.\mathrm{OCH}_{2}\right), 8.43($ br $2,1 \mathrm{H}, \mathrm{NH})$.

ANAL. Calcd for $\mathrm{C}_{4} \mathrm{H}_{5} \mathrm{NO}_{3}: \mathrm{C}, 41.74 \% ; \mathrm{H}, 4.38 \% ; \mathrm{N}$, $12.17 \%$. Found: C, $41.69 \% ; \mathrm{H}, 4.48 \% ; \mathrm{N}, 12.16 \%$.

\section{Polymerizations}

Polymerization tubes ( $10 \mathrm{~mL})$ were silanized using trimethylsilyl chloride ( $20 \mathrm{vol} \%$ in toluene), followed by repeated washings with toluene and methanol. The tubes were equipped with a stirring bar and dried at $110^{\circ} \mathrm{C}$ overnight. Subsequently the tubes were cooled to room temperature in vacuo and refilled with dry argon. Totally $5.0 \mathrm{mmol}$ of morpholine-2,5-dione and/or glycolide was weighed into the tubes. The required amount $(10-100 \mu \mathrm{L})$ of a freshly prepared $0.1 \mathrm{M}$ solution of stannous octoate in toluene was added using a glass syringe, to give the desired monomer initiator mole ratio. The solvent was removed by evaporation in vacuo. The tubes were refilled with dry argon and sealed with a rubber septum. Thereafter the tubes were purged with dry argon using stainless steel capillaries. The tubes were placed in an oil bath at $200^{\circ} \mathrm{C}$ for $3 \mathrm{~min}$, whereafter the tubes were quickly transferred to a second oil bath at the appropriate temperature. After the desired reaction time had elapsed, the tubes were removed from the oil bath and allowed to cool to room temperature. The tubes were broken, the products collected and dissolved in $10 \mathrm{ml}$ of DMSO. The resulting solutions were filtered and precipitated 
in $200 \mathrm{~mL}$ of methanol. The polymers were collected and dried in vacuo at $50^{\circ} \mathrm{C}$ for $6 \mathrm{~h}$. For ${ }^{1} \mathrm{H}-\mathrm{NMR}$, see Figure 2 later.

\section{RESULTS AND DISCUSSION}

\section{Synthesis of Morpholine-2,5-dione}

The synthesis of morpholine-2,5-dione has been described in the literature. ${ }^{14}$ Morpholine-2,5-dione was prepared in $5 \%$ yield by dry heating of the sodium salt of $\mathrm{N}$-(bromoacetyl) glycine in vacuo at 180 $200^{\circ} \mathrm{C}$. In a previous article we described the synthesis of several 3-and/or 6-alkyl-substituted morpholine-2,5-dione derivatives. ${ }^{9}$ On the basis of these results we prepared morpholine-2,5-dione (2) in $16 \%$ yield by dry heating in vacuo of the sodium salt of $\mathrm{N}$-(chloroacetyl) glycine on a matrix of Celite in the presence of a catalytic amount of antimony trioxide (Scheme 1).

\section{Homopolymerization of Morpholine-2,5-dione}

Previously we reported on the ring-opening polymerization of 3- and/or 6-alkyl-substituted morpholine-2,5-dione derivatives in the bulk using stannous octoate [tin bis (2-ethyl hexanoate)] as an initiator. ${ }^{9}$ The polymerizations were carried out at reaction temperatures of $5^{\circ} \mathrm{C}$ above the melting points of the monomers $\left(100-165^{\circ} \mathrm{C}\right)$. It was found that (3- and) 6-alkyl-substituted morpholine-2,5dione derivatives gave high molecular weight polymers with $60-70 \%$ monomer conversion after $48 \mathrm{~h}$ reaction time. Using the same reaction time (3S)methylmorpholine-2,5-dione gave only oligomers with complete conversion of monomer, where after
$1.5 \mathrm{~h}$ reaction time high molecular weight polymer was obtained with $95 \%$ conversion.

It was anticipated that morpholine-2,5-dione having no ring substituents would be more reactive than (3S) -methylmorpholine-2,5-dione, and therefore a reaction time shorter than $1.5 \mathrm{~h}$ would be sufficient. Moreover, the required reaction time might be even more reduced, because the melting point of morpholine-2,5-dione $\left(192-193^{\circ} \mathrm{C}\right)$ causes that the reaction temperature needed to perform the polymerization in the melt is much higher as compared to the temperatures employed in the polymerizations mentioned above.

Initial polymerizations of morpholine-2,5-dione were carried out at $200^{\circ} \mathrm{C}$ for 3,5 , and 15 min using stannous octoate as an initiator and a monomer to initiator mole ratio ( $\mathrm{M} / \mathrm{I})$ of 1000 (nos. 1,2 , and 3, respectively, in Table 1 ). The monomer melted within the first $2 \mathrm{~min}$ and the polymerization started. Next the melt solidified, due to the formation of polymer.

The monomer conversion was determined by ${ }^{1} \mathrm{H}$ NMR spectroscopic analysis of the crude reaction products by comparing the intensities of the $\mathrm{OCH}_{2}$ signals of the morpholine-2,5-dione $(\delta=4.72$, DMSO $\left.-d_{6}\right)$ and the corresponding signal in the polymer $(\delta=4.61)$. The conversion of morpholine2,5-dione was already $79 \%$ after 3 min reaction, and increased to $91 \%$ after $15 \mathrm{~min}$. Obviously the polymerization rate was very high during the first $3 \mathrm{~min}$, whereafter the rate decreased as a result of solidification of the reaction mixture.

A reaction time of 3 min gives poly (glycine-altglycolic acid) with the highest yield $(61 \%)$ and intrinsic viscosity ( $\eta]=0.36 \mathrm{dL} / \mathrm{g})$. After 5 min reaction time a lower yield and intrinsic viscosity were obtained, while after $15 \mathrm{~min}$ reaction time only<smiles>O=C(O)CNC(=O)CCl</smiles>

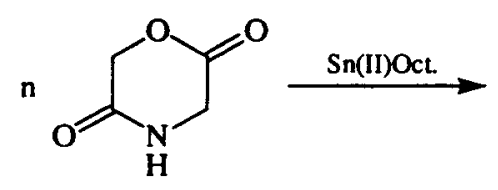

2<smiles>CCC(=O)CNC(=O)COC(C)(C)C</smiles>

3

Scheme 1. Synthesis and ring-opening polymerization of morpholine-2,5-dione. 
Table I. Ring-Opening Homopolymerization of Morpholine-2,5-dione (2) Carried Out in the Bulk with Stannous Octoate as an Initiator

\begin{tabular}{|c|c|c|c|c|c|c|}
\hline No. & $\mathrm{M} / \mathrm{I}^{\mathrm{a}}$ & $\begin{array}{c}\text { Temperature } \\
\left({ }^{\circ} \mathrm{C}\right)\end{array}$ & Time & $\begin{array}{c}\text { Conversion } \mathbf{2}^{\mathbf{b}} \\
(\%)\end{array}$ & $\begin{array}{l}\text { Yield } \\
(\%)\end{array}$ & $\begin{array}{c}{[\eta]^{\mathrm{c}}} \\
(\mathrm{dL} / \mathrm{g})\end{array}$ \\
\hline 1 & 1000 & 200 & $3 \mathrm{~min}$ & 79 & 61 & 0.36 \\
\hline 2 & 1000 & 200 & $5 \min$ & 87 & 36 & 0.33 \\
\hline 3 & 1000 & 200 & $15 \mathrm{~min}$ & 91 & 0 & - \\
\hline \multirow[t]{2}{*}{4} & 1000 & 200 & $3 \min$ & & & \\
\hline & & 100 & $17 \mathrm{~h}$ & 80 & 37 & 0.36 \\
\hline \multirow[t]{2}{*}{5} & 1000 & 200 & $3 \mathrm{~min}$ & & & \\
\hline & & 100 & $24 \mathrm{~h}$ & 82 & 39 & 0.43 \\
\hline \multirow[t]{2}{*}{6} & 1000 & 200 & $3 \mathrm{~min}$ & & & \\
\hline & & 100 & $48 \mathrm{~h}$ & 87 & 36 & 0.43 \\
\hline \multirow[t]{2}{*}{7} & 1000 & 200 & $3 \mathrm{~min}$ & & & \\
\hline & & 130 & $5 \mathrm{~h}$ & 87 & 61 & 0.35 \\
\hline \multirow[t]{2}{*}{8} & 250 & 200 & $3 \mathrm{~min}$ & & & \\
\hline & & 130 & $17 \mathrm{~h}$ & 95 & 55 & 0.38 \\
\hline \multirow[t]{2}{*}{$9^{d}$} & 1000 & 200 & $3 \mathrm{~min}$ & & & \\
\hline & & 130 & $17 \mathrm{~h}$ & 87 & 60 & 0.50 \\
\hline \multirow[t]{2}{*}{10} & 2500 & 200 & $3 \mathrm{~min}$ & & & \\
\hline & & 130 & $17 \mathrm{~h}$ & 87 & 15 & 0.40 \\
\hline \multirow[t]{2}{*}{11} & 1000 & 200 & $3 \mathrm{~min}$ & & & \\
\hline & & 130 & $24 \mathrm{~h}$ & 95 & 54 & 0.46 \\
\hline \multirow[t]{2}{*}{12} & 1000 & 200 & $3 \mathrm{~min}$ & & & \\
\hline & & 130 & $48 \mathrm{~h}$ & 97 & 43 & 0.46 \\
\hline \multirow[t]{2}{*}{13} & 1000 & 200 & $3 \mathrm{~min}$ & & & \\
\hline & & 160 & $2 \mathrm{~h}$ & 94 & 45 & 0.38 \\
\hline \multirow[t]{2}{*}{14} & 1000 & 200 & $3 \mathrm{~min}$ & & & \\
\hline & & 160 & $6 \mathrm{~h}$ & 96 & 12 & 0.30 \\
\hline \multirow[t]{2}{*}{15} & 1000 & 200 & $3 \mathrm{~min}$ & & & \\
\hline & & 160 & $17 \mathrm{~h}$ & 98 & 0 & - \\
\hline
\end{tabular}

anomer to initiator mole ratio.

${ }^{b}$ Conversion determined by ${ }^{1} \mathrm{H}-\mathrm{NMR}$.

c Intrinsic viscosity measured in DMSO at $25^{\circ} \mathrm{C}$.

${ }^{d}$ ANAL. Calcd for $\mathrm{C}_{4} \mathrm{H}_{5} \mathrm{NO}_{3}: \mathrm{C}, 41.74 \% ; \mathrm{H}, 4.38 \% ; \mathrm{N}, 12.17 \%$. Found: C, 41.69\%; H, 4.48\%; N, 12.16\%. Found: C, 40.17\%; H, 4.74\%: $\mathrm{N}, 11.62 \%$.

oligomeric products were obtained. Apparently the relatively high reaction temperature $\left(200^{\circ} \mathrm{C}\right)$ required to perform the polymerization in the melt also results in decomposition of the polymer formed. This is probably caused by backbiting reactions and/ or other side reactions between the initiator and the polymer.

To suppress these side reactions, ring-opening homopolymerization was performed for an initial 3 $\min$ at $200^{\circ} \mathrm{C}$, and the reaction was continued for different times at 100,130 , and $160^{\circ} \mathrm{C}$, respectively (Table I). The monomer conversions increased with increasing reaction times and temperatures. Prolonged reaction times and high reaction temperatures resulted in a decrease in yield and intrinsic viscosity. The highest yield (60\%) and intrinsic viscosity $([\eta]=0.50 \mathrm{dL} / \mathrm{g})$ was obtained for $3 \mathrm{~min}$ reaction at $200^{\circ} \mathrm{C}$ followed by $17 \mathrm{~h}$ reaction at $130^{\circ} \mathrm{C}$, using a $\mathrm{M} / \mathrm{I}$ ratio of 1000 . When at the same reaction temperature and time a $\mathrm{M} / \mathrm{I}$ ratio of 250 or 2500 was used, lower yields and intrinsic viscosities were obtained (nos. 8 and 10, Table I).

Previously we showed that the ring-opening polymerization of morpholine-2,5-dione derivatives in the bulk using stannous octoate as an initiator proceeds exclusively by cleavage of the ester bond. ${ }^{9}$ The same conclusion holds for the ring-opening polymerization of morpholine-2,5-dione, because ${ }^{13} \mathrm{C}$ NMR analysis of the polymers revealed only two carbonyl signals at $\delta=167.2$ and $\delta=169.0$ (DMSO$d_{6}$ ). This implies that the polymers consist of a completely alternating distribution of glycine and glycolic acid residues.

Poly (glycine-alt-glycolic acid) was insoluble in 
most organic solvents, such as chloroform, THF, DMF, and 2,2,2-trifluoroethanol. Because the polymer was only soluble in DMSO and trifluoroacetic acid, determination of the molecular weights and molecular weight distributions of the polymers using common techniques, such as GPC, was not possible.

The thermal transitions of poly (glycine-alt-glycolic acid) were studied by differential scanning calorimetry (DSC) (Fig. 1). The polymer had a glass transition temperature $\left(T_{g}\right)$ of $67^{\circ} \mathrm{C}$, a melting point $\left(T_{m}\right)$ of $199^{\circ} \mathrm{C}$, and a heat of fusion $(\Delta H)$ of 16.2 $\mathrm{J} / \mathrm{g}$. Prior to the melting peak recrystallization was observed at $T=170^{\circ} \mathrm{C}$. After quenching from 220 to $-10^{\circ} \mathrm{C}$, a $T_{g}$ of $66^{\circ} \mathrm{C}$, a $T_{m}$ of $192^{\circ} \mathrm{C}$, a $\Delta H$ value of $14.5 \mathrm{~J} / \mathrm{g}$, and recrystallization at $154^{\circ} \mathrm{C}$ was observed.

\section{Copolymerization of Morpholine-2,5-dione and Glycolide}

The ring-opening copolymerization of morpholine2,5-dione (2) with glycolide was performed using the optimal reaction conditions observed for the homopolymerization of $\mathbf{2}$, i.e., using stannous octoate as an initiator with a $\mathrm{M} / \mathrm{I}$ ratio of $1000,3 \mathrm{~min}$ reaction at $200^{\circ} \mathrm{C}$ followed by $17 \mathrm{~h}$ reaction at $130^{\circ} \mathrm{C}$. The mole fraction of morpholine-2,5-dione in the feed $\left(x_{\mathrm{M}}\right)$ was varied between 1 and 0.50 (Table II). Copolymers with $x_{M}<0.50$ were also prepared, but analogously to poly (glycolic acid) these materials were insoluble in common organic solvents, which prevented purification and analysis of these polymers.

The conversion of morpholine-2,5-dione in the copolymerization reactions was between 95 and $97 \%$, while the conversion of glycolide was always over $99 \%$. The copolymers were obtained in $55-63 \%$ yield. The mole fraction of morpholine-2,5-dione in the

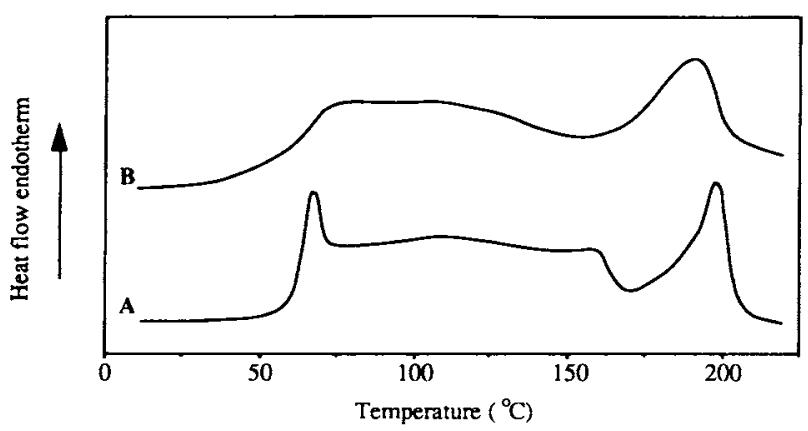

Figure 1. DSC trace of poly (glycine-alt-glycolic acid) (no. 9, Table I): (A) first scan, (B) second scan after quenching from 220 to $-10^{\circ} \mathrm{C}$.
Table II. Ring-Opening Copolymerization of Morpholine-2,5-dione (2) and Glycolide Carried out in the Bulk at $200^{\circ} \mathrm{C}$ for $3 \mathrm{Min}$ and Continued at $130^{\circ} \mathrm{C}$ for $17 \mathrm{~h}$, Using Stannous Octoate as an Initiatior with a Mole Ratio M/I of 1000

\begin{tabular}{lllccccc}
\hline & & & Yield & $\begin{array}{c}{[\eta]^{\mathrm{c}}} \\
(\%)\end{array}$ & $\begin{array}{c}T_{g}^{\mathrm{d}} \\
(\mathrm{dL} / \mathrm{g})\end{array}$ & $\begin{array}{c}T_{m}{ }^{\mathrm{d}} \\
\left({ }^{\circ} \mathrm{C}\right)\end{array}$ & $\begin{array}{c}\left.\Delta{ }^{\circ} \mathrm{C}\right) \\
(\mathrm{J} / \mathrm{g})\end{array}$ \\
\hline 1 & 1 & 1 & 60 & 0.50 & 67 & 199 & 16.2 \\
2 & 0.90 & 0.89 & 56 & 0.33 & 57 & 163 & 14.9 \\
$3^{\mathbf{e}}$ & 0.80 & 0.79 & 59 & 0.40 & 51 & 142 & 10.6 \\
$4^{\mathrm{f}}$ & 0.70 & 0.69 & 57 & 0.38 & 50 & - & - \\
5 & 0.60 & 0.58 & 63 & 0.41 & 51 & 142 & 15.5 \\
6 & 0.50 & 0.48 & 56 & 0.39 & 48 & 162 & 51.3 \\
7 & 0 & $-{ }^{\mathrm{g}}$ & $-{ }^{\mathrm{g}}$ & $-{ }^{\mathrm{g}}$ & - & 219 & 108 \\
\hline
\end{tabular}

a Mole fraction of $\mathbf{2}$ in the feed of the copolymerization.

${ }^{b}$ Mole fraction of 2 in copolymer determined by ${ }^{1} \mathrm{H}-\mathrm{NMR}$.

' Intrinsic viscosity measured in DMSO at $25^{\circ} \mathrm{C}$.

${ }^{d}$ Determined by DSC analysis from the first scan.

e ANAL. Calcd for $\left[\left(\mathrm{C}_{4} \mathrm{H}_{5} \mathrm{NO}_{3}\right)_{0.79}\left(\mathrm{C}_{4} \mathrm{H}_{4} \mathrm{O}_{4}\right)_{0.21}\right]_{\mathrm{n}}: \mathrm{C}, 41.67 \% ; \mathrm{H}$, $4.19 \%$; N, $9.60 \%$. Found: $\mathrm{C}, 40.52 \% ; \mathrm{H}, 4.15 \% ; \mathrm{N}, 9.29 \%$.

${ }^{f}$ ANAL. Calcd for $\left[\left(\mathrm{C}_{4} \mathrm{H}_{5} \mathrm{NO}_{3}\right)_{0.69}\left(\mathrm{C}_{4} \mathrm{H}_{4} \mathrm{O}_{4}\right)_{0.31}\right]_{\mathrm{n}}: \mathrm{C}, 41.64 \% ; \mathrm{H}$, $4.10 \%$; N, $8.38 \%$. Found: C, $40.55 \% ; \mathrm{H}, 4.20 \% ; \mathrm{N}, 8.01 \%$.

${ }^{\mathrm{B}}$ Not determined.

copolymers $\left(X_{\mathrm{M}}\right)$ was equal to the mole fractions of morpholine-2,5-dione in the feed of the reactions $\left(x_{M}\right)$. The intrinsic viscosities of the copolymers $([\eta]$ $=0.33-0.41 \mathrm{dL} / \mathrm{g})$ were somewhat lower as observed for poly (glycine-alt-glycolic acid) $([\eta]=0.50 \mathrm{dL} /$ g) prepared under the same reaction conditions.

Recently we reported on the ${ }^{13} \mathrm{C}$-NMR sequence analysis of copolymers of 3-and/or 6-alkyl-substituted morpholine-2,5-dione derivatives and $\epsilon$-caprolactone. ${ }^{12}{ }^{1} \mathrm{H}$-NMR spectroscopy proved to be less sensitive to sequence effects and therefore could not be used for sequence analysis of copolymers of morpholine-2,5-dione derivatives and $\epsilon$-caprolactone. In contrast to this, the ${ }^{1} \mathrm{H}-\mathrm{NMR}$ methylene proton signals of the glycolyl moieties of the glycine/glycolic acid based copolymers appeared to be very sensitive to sequence effects. The methylene protons of the glycolyl moieties showed a triad sensitivity. The assignment of the glycolyl methylene signals in the ${ }^{1} \mathrm{H}$-NMR spectra ( Fig. 2) to the possible triads is based on the above mentioned conclusion that ringopening polymerization of morpholine-2,5-dione proceeds exclusively by cleavage of the ester bond. The peaks $h$ and $h^{3}$ were assigned on the basis of the ${ }^{1} \mathrm{H}$-NMR chemical shifts of the glycolyl methylene protons of the homopolymers, i.e., poly(glycine-alt-glycolic acid) and poly(glycolic acid), respectively. Replacing a glycolyl unit for a glycyl unit in the $\mathrm{H}-\mathrm{H}-\mathrm{H}$ triad causes an upfield shift of the methylene protons of the central glycolyl 

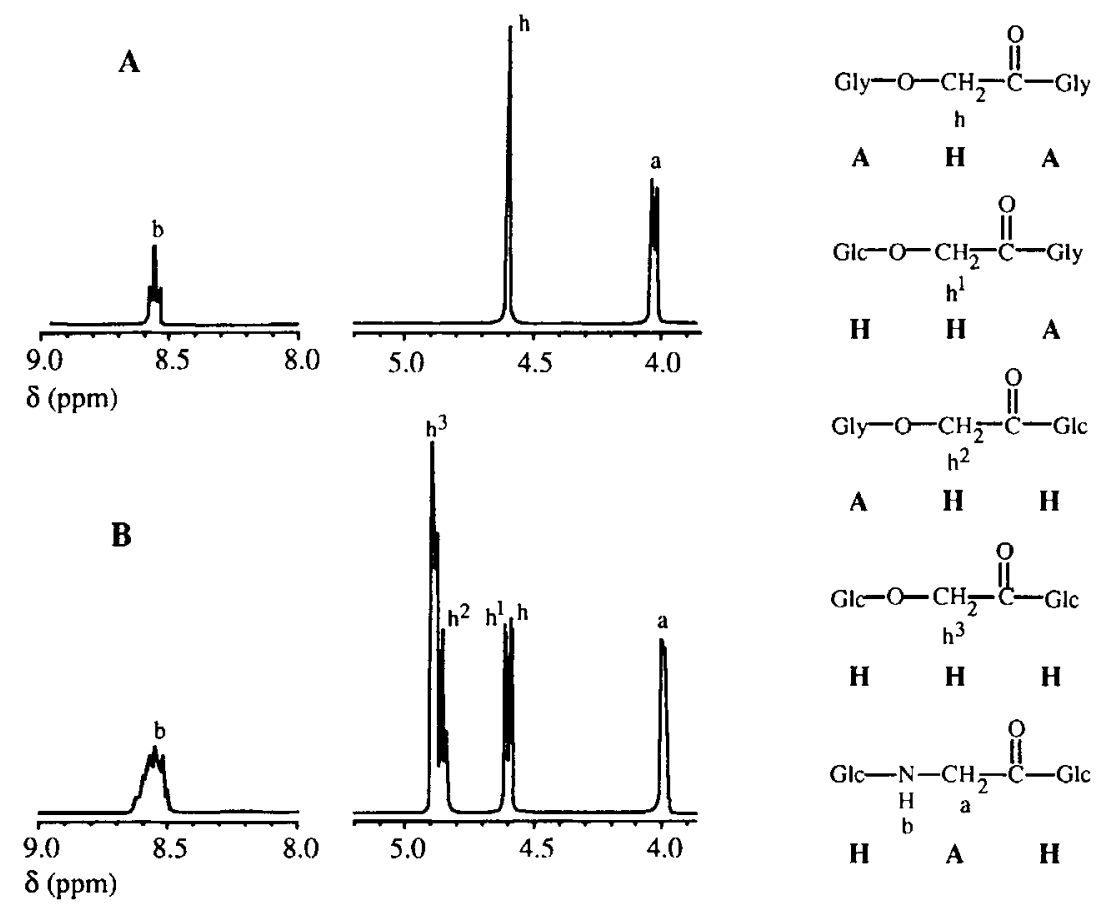

Figure 2. ${ }^{1} \mathrm{H}-\mathrm{NMR}$ spectra (DMSO- $d_{6}$ ) of: (A) poly (glycine-alt-glycolic acid) and (B) copolymer of morpholine-2,5-dione and glycolide with $X_{\mathrm{M}}=0.48$ (Gly = glycine residue, Glc $=$ glycolic acid residue $)$.

unit. Since the upfield shift is expected to be smaller on the central glycolyl unit in the $\mathrm{A}-\mathrm{H}-\mathrm{H}$ triad than in the $\mathrm{H}-\mathrm{H}-\mathrm{A}$ triad, peak $\mathrm{h}^{2}$ was assigned to the $\mathrm{A}-$ $\mathrm{H}-\mathrm{H}$ sequence and peak $\mathrm{h}^{1}$ to the $\mathrm{H}-\mathrm{H}-\mathrm{A}$ sequence.

For a random copolymerization the number of $\mathrm{H}-\mathrm{H}-\mathrm{A}$ and $\mathrm{A}-\mathrm{H}-\mathrm{H}$ triads must be identical. This implies that peaks $h^{1}$ and $h^{2}$ must have equal intensities. All copolymers synthesized had equal $h^{1}$ and $h^{2}$ signal intensities in their ${ }^{1} \mathrm{H}$-NMR spectra, confirming a random copolymerization.

For the copolymer with $X_{\mathrm{M}}=0.48$ a signal intensity ratio $h: h^{1}: h^{2}: h^{3}=3.28: 1.04: 1: 1$ was found. This is in good agreement with the theoretical ratio for a random copolymer with $X_{M}=0.48$, i.e., $h: h^{1}: h^{2}: h^{3}=3.43: 1.09: 1.09: 1$. Also the observed $h: h^{1}: h^{2}: h^{3}$ intensity ratios for the other copolymer compositions were in accordance with the theoretical ratios for a random copolymer. This indicates that the copolymers of morpholine-2,5-dione and glycolide consisted of a random sequence distribution of glycyl and glycolyl units.

Because ring-opening polymerization of morpholine-2,5-dione exclusively proceeds by cleavage of the ester bond, the existence of only one glycyl triad is possible, namely $\mathrm{H}-\mathrm{A}-\mathrm{H}$ (Fig. 2). Therefore for the glycyl moieties only one signal is expected in the ${ }^{1} \mathrm{H}$-NMR spectra of the copolymers [Fig. 2(b), peak a ], similar to the ${ }^{1} \mathrm{H}$-NMR spectrum of the alternating homopolymer poly (glycine-alt-glycolic acid) [Figure 2(a), peak a].

The copolymers had single glass transition temperatures $\left(T_{g}\right)$ and melting temperatures $\left(T_{m}\right)$ (Table II), confirming that the copolymers investigated are random copolymers. This is in good agreement with the results obtained by ${ }^{1} \mathrm{H}-\mathrm{NMR}$ sequence analysis. The $T_{g}$ values ranged from 57 to $48^{\circ} \mathrm{C}$, and tended to decrease slightly with $X_{\mathrm{M}}$. The $T_{m}$ values and the heats of fusion $(\Delta H)$ both decreased with decreasing $X_{\mathrm{M}}$ up to $X_{\mathrm{M}}=0.79$. The copolymer with $X_{\mathrm{M}}=0.69$ was completely amorphous. Next the $T_{m}$ and $\Delta H$ values increased again with decreasing $X_{\mathrm{M}}$. However, the $\Delta H$ values were larger as compared to the values for the copolymers with $X_{\mathrm{M}}>0.69$. Obviously the copolymers with $X_{\mathrm{M}}>0.69$ contain blocks of glycyl-alt-glycolyl moieties, which are able to crystallize. With increasing $X_{\mathrm{M}}$ the crystallization of glycyl-alt-glycolyl blocks becomes more difficult, due to the random incorporation of glycolyl moieties. Copolymers with $X_{M}<0.69$ contain crystallizable blocks of glycolyl moieties.

As mentioned above poly (glycine-alt-glycolic acid) had after quenching from 220 to $-10^{\circ} \mathrm{C}$ a melting endotherm in the second scan. In contrast to this the semi-crystalline copolymers of morpho- 
line-2,5-dione and glycolide had not a melting endotherm in the second scan.

\section{CONCLUSIONS}

Semi-crystalline poly (glycine-alt-glycolic acid) was prepared by ring-opening polymerization of morpholine-2,5-dione in the bulk using stannous octoate as an initiator. At high reaction temperatures the polymerization was accompanied by backbiting and/ or decomposition reactions, leading to low molecular weight products. Random copolymers of glycine and glycolic acid were synthesized by ring-opening copolymerization of morpholine-2,5-dione and glycolide in the bulk. The morphology of the copolymers varied from semi-crystalline to amorphous, depending on the mole fraction of glycolyl units incorporated.

The authors would like to thank the WHO for support (Research Training Grant to Z. S.).

\section{REFERENCES AND NOTES}

1. M. Vert, S. M. Li, G. Spenlehauer, and P. Guerin, $J$. Mater. Sci. Mater. Med., 3, 432 (1992).
2. A. U. Daniels, M. K. O. Chang, K. P. Andriano, and J. Heller, J. Appl. Biomater., 1, 57 (1990).

3. F. H. C. Stewart, Aust. J. Chem., 22, 1291 (1969).

4. D. Nissen, C. Gilon, and M. Goodman, Makromol. Chem. Suppl., 1, 23 (1975).

5. R. Katakai and M. Goodman, Macromolecules, 15, 25 (1982).

6. R. Katakai, J. Chem. Soc. Perkin, 1, 2249 (1987).

7. M. Yoshida, M. Asano, M. Kumakura, R. Katakai, T. Mashimo, H. Yuasa, K. Imai, and H. Yamanaka, J. Biomed. Mater. Res., 24, 1173 (1990).

8. J. Helder, F. E. Kohn, S. Sato, J. W. van den Berg, and J. Feijen, Makromol. Chem. Rapid Commun., 6, $9(1985)$.

9. P. J. A. in 't Veld, P. J. Dijkstra, J. H. van Lochem, and J. Feijen, Makromol. Chem., 191, 1813 (1990).

10. J. Helder, S. J. Lee, S. W. Kim, and J. Feijen, Makromol. Chem. Rapid Commun., 7, 193 (1986).

11. Pfizer Inc. invs.: F.-N. Fung, R. C. Glowaky, Eur. Pat. Appl. EP 322,154 (1989).

12. P. J. A. in 't Veld, Ye Wei-ping, R. Klap, P. J. Dijkstra, and J. Feijen, Makromol. Chem., 193, 1927 (1992).

13. P. J. A. in 't Veld, P. J. Dijkstra, and J. Feijen, Makromol. Chem. 193, 2713 (1992).

14. Ethicon Inc., invs.: S. W. Shakaby, D. F. Koelmel, Eur. Pat. Appl. 86,613 (1983).

Received May 31, 1993

Accepted September 29, 1993 